\title{
Utilization willingness of institutional care between disabled and non-disabled seniors: evidence from Jiangsu, China
}

\author{
$\mathrm{Na}$ Chen ${ }^{1}$, Xin $\mathrm{Li}^{2}$, Ni Yuan ${ }^{3}$, Cheng-chao Zhou ${ }^{4^{*}}$ and Chang-qing Wang ${ }^{5^{*}}$
}

\begin{abstract}
Background: Due to rapidly growing number of old adults and diminishing supportive functions of family in China, the issue of willingness to use institutional care is of high priority, especially for disabled seniors. The objective of this study is to compare the willingness of institutional care and its determinants between disabled and non-disabled seniors in China.

Methods: 2493 seniors (60+) were randomly selected from a cross-sectional study conducted in three urban districts and three rural counties in Jiangsu Province. Binary logistic regression model was employed to examine differences towards the preference for institutional care between two subgroups, and to identify factors associated with willingness of institutional care between disabled and non-disabled seniors.

Results: Of 2493 respondents, 402 (16.1\%) were disabled seniors. Overall, 14.2\% of the participants had willingness for institutional care in Jiangsu, China. The willingness for institutional care among non-disabled seniors ( $O R=0.513$; $95 \% \mathrm{Cl}$ 0.387-9.680) was significantly lower than that among disabled ones. The preference for institutional care of both disabled and non-disabled seniors was associated with household income. The willingness of institutional care was also related to age, education and living arrangement among disabled seniors. Meanwhile, non-disabled seniors who had non-communicable diseases were found to be more likely to choose elder care in institution.

Conclusions: Our findings indicated that the willingness for institutional care among disabled seniors was significantly higher than that among non-disabled ones. Household income was determinant of utilization willingness for institutionalization both in disabled and non-disable seniors. Different policies should be made or modified for disabled and non-disabled seniors separately.
\end{abstract}

Keywords: Willingness, Institutional care, Disabled seniors, Non-disabled seniors, China

\section{Background}

As the world's most populous country with the largest number of aging population [1], China has experienced an unprecedented aging process because of extending life expectancy and reducing mortality. In 2016, 16.7\% of Chinese population (230.86 million) were aged 60 and above [2]. The older adults are predicted to account for $33 \%$ of the total population in China by 2050 [3]. With increasing and aging population, it is a persistent

\footnotetext{
*Correspondence: zhouchengchao@sdu.edu.cn; cqwang1962@163.com ${ }^{4}$ School of Public Health, Shandong University, 44 Wen-hua-xi Road, Jinan 250100, Shandong, China

${ }^{5}$ Nanjing Medical University, 101 Longmian Road, Nanjing 211166, Jiangsu, China

Full list of author information is available at the end of the article
}

challenge for China to take better care of elders, especially disabled seniors. The disabled seniors refer to those older adults with activity of daily living (ADL) disability, which is assessed by instruments using the International Classification of Functioning, Disability, and Health framework [4]. A nation-wide sample survey indicated that there were 40.63 million disabled seniors in 2015 , accounting for $18.3 \%$ of the total older adults in China [5].

Despite the increasing percentage of elders, supportive functions of family are diminishing. Filial piety is the basic norm in the Confucian doctrine [6], which means that adult children have responsibility to take care of older people. However, supportive functions of family to

(C) The Author(s). 2019 Open Access This article is distributed under the terms of the Creative Commons Attribution 4.0 International License (http://creativecommons.org/licenses/by/4.0/), which permits unrestricted use, distribution, and 
take care of older adults are immensely weakened due to decreasing family size and increasing demographic shift $[7,8]$. "4:2:1"family structure (four grandparents, two adult children, and one grandchild) poses a dilemma for the adults who have to look after four parents and take care of one child at the same time [9]. The phenomenon is likely to become even more pressing in the near future with the implementation of universal two-child policy.

Due to diminishing supportive functions of family and rapid growth of older adults, especially the increasing percentage of disabled seniors in China [10], exploring the willingness of institutional care and its influential factors are of high priority. Several previous studies have identified determinants of willingness for institutional care, such as age [11, 12], gender [13], income [11], education [12, 14], marital status [11, 12], living arrangements [11-13], non-communicable disease (NCDs) [15], and insurance [16]. However, few studies have explored the willingness of institutional care among disabled seniors [17], and no studies have compared such willingness between disabled and non-disabled seniors in China [18]. To remedy the situation, this study aims to explore the disparity in utilization willingness of institutional care between disabled and non-disabled seniors in China. To do so, we have following specific objectives. First, we will compare the preference for institutionalized care between disabled and non-disabled seniors. Second, we will identify influential factors of the willingness for institutional care among disabled and nondisabled seniors separately.

\section{Methods}

\section{Study setting and study population}

This cross-sectional study was conducted in Jiangsu province. Jiangsu ranks the third in terms of population in China. Moreover, this province has the most percentage of seniors, in which the older adults aged 60 and above account for $21.4 \%$ of the total population (about 16.48 million) in 2015 [19]. The percentage is much higher than the national average.

Three-stage cluster sampling method was adopted to select participants. First, we divided the urban districts and rural counties into three categories according to GDP (Gross domestic product) per capita (2015). Then one county and one district were randomly selected from each category. Therefore, three urban counties (Gusu, Qinghe, Haizhou) and three rural districts (Liyang, Xinghua, Xinyi) were confirmed as study sites. Next, three levels of townships and sub-district were randomly stratified from each sampling county and district in the same way. Finally, three villages and three communities were randomly selected from each subgroup. In all, a total of 2700 seniors were recruited, of which 2493 ones with complete data from 27 rural village and 27 urban communities were included in the analysis.

\section{Data collection}

The data was collected from June to August in 2016 by using face-to-face interview. The standard structured questionnaire was composed of social demographic characteristics, living arrangement, health insurance, household income, and willingness of institutional care. In order to ensure quality, the cross-sectional study was conducted by trained postgraduate students from Nanjing University of Chinese Medicine. Participants were informed about the aim of the survey, the selection criterion of the sample, and the assurance that the information was only used for research. Furthermore, the proxy consent procedure was given for those participants who were considered cognitively impaired. All participants gave written informed consent before inclusion in the study. The Cronbach's Alpha of the total questionnaire is 0.784 , indicating a high reliability.

\section{Variables and measures Dependent variables}

The willingness of institutional care was defined as dependent variables, measuring by the question, 'which way of old-age pension are you willing for?' If the answer was 'institutional care', then 'yes' was coded. On the contrary, if the older people choose 'home-based care' or 'community-based care', the dependent variable was defined as 'no'.

\section{Independent variables}

On the basis of Andersen-Nyman model [18, 20, 21], we classified explanatory factors into three categories and choosing appropriate variables: 1) Predisposing variables, including gender (female, male), age (60-69, 70-79,80+), marital status (married or others), and education (primary school or below, junior school, high school or above). 2) Enabling variables, including residence (urban or rural), living arrangements (living alone, living with children or others), health insurance (New cooperative medical scheme (NCMS), Medical insurance for urban residents' scheme (MIUR), Medical insurance for urban employee scheme (MIUE), others including commercial insurance), and household income (Q1, Q2, Q3 andQ4). According to the Jiangsu Statistical Yearbook, we adopted quartile to divide the household income into four groups. Quartile 4 (Q4) is the richest and Quartile 1 (Q1) is the poorest. 3) Need variables, consisted of ADL disability (yes or no) and NCDs including hypertension, diabetes, Heart disease, stroke, rheumatism, Alzheimer's disease et al. (yes or no).

The ADL disability was measured by Katz Index Scale [22-25], which included the following six items: feeding, 
dressing, bathing, toileting, walking inside, bladder and bowel control. Each item had two response choices: "dependent" and "independent". If any answer was "dependent", the seniors were categorized as older adults with ADL disability which means needing equipment or human help to complete the above task, otherwise, the seniors were defined as non-disabled ones without ADL disability. The Chinese version scale was proven to be of good validity and reliability [26].

\section{Statistical analysis}

The data were double entered and checked by Epi Data V.3.02. The statistical package SPSS V.20.0 was employed to analyze the data. Chi-square test was performed to examine differences in the independent variables mentioned above between disabled and nondisabled seniors. Binary logistic regression was applied to assess the association of willingness to live in institution with the ADL disability among old adults, and to identify the explanatory factors between disabled and non-disabled seniors separately. All reported CIs were calculated at the $95 \%$ level. Statistical significance was set at the $5 \%$ level.

\section{Results}

\section{Basic information of the participants}

As shown in Table 1, 14.2\% of the participants had willingness for institutional care in Jiangsu, China. The proportion of disabled and non-disabled seniors who preferred institutional care was 22.6 and $12.6 \%$ separately. Of all respondents, the majority of seniors were non-disabled (83.9\%), at the ages of 70-79 (51.3\%), female (52.7), married (75.2\%), having education level of primary or below $(64.4 \%)$, rural (63.5\%), living with children or others $(86.8 \%)$, covered by NCMS (55.7\%), the poorest $(47.9 \%)$, and having NCDs $(87.3 \%)$. In general, age $(P<0.001)$, marital status $(P<0.001)$, living arrangement $(P<0.001)$, household income $(P=0.002)$ and NCDs $(P<0.001)$ were significantly different between non-disabled and disabled seniors.

\section{Association of willingness for institutional care and ADL disability among seniors}

Table 2 showed the disparity of willingness to live in institution between disabled and non-disabled seniors in two models. Results from model 1 identified that willingness was statistically higher among disabled seniors (OR $=0.494$, 95CI 0.378-0.645, $P<0.001)$. Model 2 indicated that when controlling other variables, willingness of institutional care among disabled seniors was also significantly higher than that among non-disabled seniors (OR $=0.513$, 95CI 0.387-9.680, $P<0.001)$.
Factors associated with willingness for institutional care among disabled seniors

We identified the factors associated with the willingness to live in institution among disabled seniors (Table 3). Univariate analysis showed that eight factors were found to be statistically significant $(P<0.05)$ related to the willingness of institutional care, including age, gender, marital status, education status, residence, household income. Multi-logistic regression showed that disabled seniors who were aged from 60 to $80(P<0.001)$, who lived alone $(P=0.023)$, whose household income was corresponding to Q3 $(P=0.025)$ preferred choosing institutional care, and those who had lower educational level $(P<0.001)$ did not prefer institutional care.

\section{Factors associated with willingness for institutional care among non-disabled seniors}

The influential factors associated with willingness of institutional care among non-disabled seniors showed in Table 4. The univariate analysis indicated that the nondisabled seniors who were married $(P=0.006)$, whose household income belonged to Q2 $(P=0.001)$, who had no NCDs $(P=0.002)$ were less likely to choose institutional care. Those who lived alone $(P=0.007)$, who were not covered by any medical insurance $(P=0.022)$ preferred institutional care. Multi-logistic regression showed that two factors from the above five items were still significantly associated with the willingness, including NCDs and household income.

\section{Discussion}

Based on the cross-sectional study conducted in Jiangsu, our study compared the willingness of institutional care between disabled and non-disabled seniors in China and explored determinants in two subgroups separately. To our knowledge, it is the first study that focuses on the research subject above. Our findings showed that the willingness for institutional care among disabled seniors was significantly higher than non-disabled old adults.

Our study found that $14.2 \%$ of seniors chose institutional care. The percentage was lower than $45 \%$ which was reported in America [27] and 16.7\% demonstrated in Taiwan [28]. Compared with studies of other provinces, the proportion was also lower than Beijing (30\%) [29], Henan (16.1\%) [16] and Guizhou (38.5\%) [14]. However, it was higher than Shandong (8.5\%) [30] and Zhejiang province [31]. In different circumstance, there is a large disparity of preference for institutional care among the seniors.

Consistent with other studies [32, 33], the result of our study demonstrated there was a significant difference in willingness of institutional care between two subgroups. The proportion of disabled and non-disabled seniors who preferred institutional care was 22.6 and 
Table 1 Characteristics of the sample in Jiangsu, China (2016)

\begin{tabular}{|c|c|c|c|c|c|c|c|}
\hline \multirow[t]{2}{*}{ Characteristics } & \multirow{2}{*}{$\begin{array}{l}\text { Total } \\
\mathrm{n}\end{array}$} & \multirow[b]{2}{*}{$\%$} & \multicolumn{2}{|c|}{ Non-disabled seniors } & \multicolumn{2}{|c|}{ Disabled seniors } & \multirow[t]{2}{*}{$P$} \\
\hline & & & $\mathrm{n}$ & $\%$ & $\mathrm{n}$ & $\%$ & \\
\hline Observation & 2493 & 100.0 & 2091 & 83.9 & 402 & 16.1 & \\
\hline Willingness of institutional care & 355 & 14.2 & 264 & 12.6 & 91 & 22.6 & $<0.001$ \\
\hline \multicolumn{8}{|l|}{ Predisposing factors } \\
\hline Age & & & & & & & $<0.001$ \\
\hline $60-69$ & 858 & 34.4 & 773 & 37.0 & 85 & 21.1 & \\
\hline $70-79$ & 1278 & 51.3 & 1083 & 51.8 & 195 & 48.5 & \\
\hline $80+$ & 357 & 14.3 & 235 & 11.2 & 122 & 30.4 & \\
\hline Gender & & & & & & & 0.413 \\
\hline Female & 1314 & 52.7 & 1110 & 53.1 & 204 & 50.7 & \\
\hline Male & 1179 & 47.3 & 981 & 46.9 & 198 & 49.3 & \\
\hline Marital status & & & & & & & $<0.001$ \\
\hline Married & 1874 & 75.2 & 1619 & 77.4 & 255 & 63.4 & \\
\hline Others & 619 & 24.8 & 472 & 22.6 & 147 & 36.6 & \\
\hline Education & & & & & & & 0.091 \\
\hline Primary or below & 1606 & 64.4 & 1328 & 63.5 & 278 & 69.2 & \\
\hline Junior & 581 & 23.3 & 498 & 23.8 & 83 & 20.6 & \\
\hline High or above & 306 & 12.3 & 265 & 12.7 & 41 & 10.2 & \\
\hline \multicolumn{8}{|l|}{ Enabling factors } \\
\hline Residence & & & & & & & 0.101 \\
\hline Urban & 909 & 36.5 & 777 & 37.2 & 132 & 32.8 & \\
\hline Rural & 1584 & 63.5 & 1314 & 62.8 & 270 & 67.2 & \\
\hline Living arrangements & & & & & & & $<0.001$ \\
\hline Alone & 330 & 13.2 & 243 & 11.6 & 87 & 21.6 & \\
\hline With children or others & 2163 & 86.8 & 1848 & 88.4 & 315 & 78.4 & \\
\hline Insurance ${ }^{a}$ & & & & & & & 0.335 \\
\hline None & 96 & 3.9 & 74 & 3.5 & 22 & 5.5 & \\
\hline MIUE & 340 & 13.6 & 291 & 13.9 & 49 & 12.2 & \\
\hline MIUR & 595 & 23.9 & 499 & 23.9 & 96 & 23.9 & \\
\hline NCMS & 1389 & 55.7 & 1168 & 55.9 & 221 & 55.0 & \\
\hline Others & 73 & 2.9 & 59 & 2.8 & 14 & 3.5 & \\
\hline Household income ${ }^{b}$ & & & & & & & 0.002 \\
\hline $\mathrm{Q}_{4}$ & 117 & 4.7 & 100 & 4.8 & 17 & 4.2 & \\
\hline $\mathrm{Q}_{3}$ & 327 & 13.1 & 268 & 12.8 & 59 & 14.7 & \\
\hline $\mathrm{Q}_{2}$ & 855 & 34.3 & 749 & 35.8 & 106 & 26.4 & \\
\hline $\mathrm{Q}_{1}$ & 1194 & 47.9 & 974 & 46.6 & 220 & 54.7 & \\
\hline \multicolumn{8}{|l|}{ Need factors } \\
\hline$N C D^{c}$ & & & & & & & $<0.001$ \\
\hline Yes & 2176 & 87.3 & 1797 & 85.9 & 379 & 94.3 & \\
\hline No & 317 & 12.7 & 294 & 14.1 & 23 & 5.7 & \\
\hline
\end{tabular}

${ }^{a}$ NCMS New cooperative medical scheme, MIUR Medical insurance for urban residents scheme, MIUE Medical insurance for urban employee scheme ${ }^{\mathrm{b}}$ Quartile 4 (Q4) is the richest and Quartile 1 (Q1) is the poorest

${ }^{\mathrm{N}} \mathrm{NCD}$ Non-communicable chronic disease 
Table 2 Association of ADL disability and willingness for institutional care among seniors in Jiangsu, China,2016

\begin{tabular}{|c|c|c|c|c|}
\hline \multirow[t]{2}{*}{ Characteristics } & \multicolumn{2}{|c|}{ Model 1(No covariates) } & \multicolumn{2}{|l|}{ Model 2 (Covariates) } \\
\hline & OR $(95 \% \mathrm{Cl})$ & $P$ & OR $(95 \% \mathrm{Cl})$ & $P$ \\
\hline \multicolumn{5}{|l|}{ ADL disability } \\
\hline No & $0.494(0.378-0.645)$ & $<0.001$ & $0.513(0.387-9.680)$ & $<0.001$ \\
\hline Yes & 1.0 & & 1.0 & \\
\hline \multicolumn{5}{|l|}{ Age } \\
\hline $60-69$ & & & 2.003(1.339-2.997) & 0.001 \\
\hline 70-79 & & & $1.650(1.130-2.410)$ & 0.010 \\
\hline $80+$ & & & 1.0 & \\
\hline \multicolumn{5}{|l|}{ Gender } \\
\hline Male & & & $1.122(0.880-1.430)$ & 0.352 \\
\hline Female & & & 1.0 & \\
\hline \multicolumn{5}{|l|}{ Marital status } \\
\hline Married & & & $0.806(0.598-1.087)$ & 0.158 \\
\hline Others & & & 1.0 & \\
\hline \multicolumn{5}{|l|}{ Education } \\
\hline Primary or below & & & $0.615(0.412-0.918)$ & 0.017 \\
\hline Junior & & & $0.714(0.476-1.070)$ & 0.103 \\
\hline High or above & & & 1.0 & \\
\hline \multicolumn{5}{|l|}{ Residence } \\
\hline Urban & & & $1.053(0.771-1.437)$ & 0.747 \\
\hline Rural & & & 1.0 & \\
\hline \multicolumn{5}{|l|}{ Living arrangements } \\
\hline Alone & & & $1.542(1.096-2.170)$ & 0.013 \\
\hline With children or others & & & 1.0 & \\
\hline \multicolumn{5}{|l|}{ Insurance ${ }^{a}$} \\
\hline None & & & $0.679(0.320-1.442)$ & 0.314 \\
\hline MIUE & & & $0.883(0.437-1.783)$ & 0.729 \\
\hline MIUR & & & $0.940(0.477-1.852)$ & 0.859 \\
\hline NCMS & & & 1.158(0.498-2.694) & 0.734 \\
\hline Others & & & 1.0 & \\
\hline \multicolumn{5}{|l|}{ Household income $^{b}$} \\
\hline $\mathrm{Q}_{4}$ & & & $0.918(0.508-1.657)$ & 0.776 \\
\hline $\mathrm{Q}_{3}$ & & & $1.008(0.682-1.490)$ & 0.969 \\
\hline $\mathrm{Q}_{2}$ & & & $0.616(0.458-0.828)$ & 0.001 \\
\hline $\mathrm{Q}_{1}$ & & & 1.0 & \\
\hline \multicolumn{5}{|l|}{$N C D^{c}$} \\
\hline No & & & $0.420(0.266-0.663)$ & $<0.001$ \\
\hline Yes & & & 1.0 & \\
\hline
\end{tabular}

${ }^{\mathrm{a}} A D L$ activity of daily living

${ }^{b}$ NCMS New cooperative medical scheme, MIUR Medical insurance for urban residents scheme, MIUE Medical insurance for urban employee scheme ${ }^{c}$ Quartile $4(\mathrm{Q} 4)$ is the richest and Quartile $1(\mathrm{Q} 1)$ is the poorest

${ }^{\mathrm{d} N C D}$ Non-communicable chronic disease

$12.6 \%$ separately. However, another study [18] which revealed that disabled seniors were less likely to choose institutional care. One possible explanation is that attitudinal changes towards institutional care is happening in China in recent years [34]. More and more aging adults, especially disabled seniors recognize that 
Table 3 Factors associated with willingness of institutional care among disabled seniors in Jiangsu, China, 2016 ( $n=402)$

\begin{tabular}{|c|c|c|c|c|c|c|}
\hline \multirow[t]{2}{*}{ Characteristics } & \multicolumn{2}{|c|}{ Willingness of institutional care } & \multirow[t]{2}{*}{$\mathrm{OR}_{C}(95 \% \mathrm{Cl})$} & \multirow[t]{2}{*}{$P$} & \multirow[t]{2}{*}{$\mathrm{OR}_{\mathrm{a}}(95 \% \mathrm{Cl})$} & \multirow[t]{2}{*}{$P$} \\
\hline & No (\%) & Yes (\%) & & & & \\
\hline$N=402$ & $311(77.4)$ & $91(22.6)$ & & & & \\
\hline \multicolumn{7}{|l|}{ Age } \\
\hline $60-69$ & $61(71.8)$ & $24(28.2)$ & $3.299(1.567-6.943)$ & 0.002 & $4.310(1.882-9.869)$ & 0.001 \\
\hline $70-79$ & $141(72.3)$ & $54(27.2)$ & $3.211(1.668-6.182)$ & $<0.001$ & $3.836(1.842-7.985)$ & $<0.001$ \\
\hline $80+$ & 109(89.3) & 13(10.7) & 1 & & 1 & \\
\hline \multicolumn{7}{|l|}{ Gender } \\
\hline Male & 143(72.2) & $55(27.8)$ & $1.795(1.115-2.888)$ & 0.016 & $1.629(0.956-2.774)$ & 0.072 \\
\hline Female & 168(82.4) & $36(17.6)$ & 1 & & 1 & \\
\hline \multicolumn{7}{|l|}{ Marital status } \\
\hline Married & 194(76.1) & $61(23.9)$ & $1.795(1.115-2.888)$ & 0.016 & 1.213(0.633-2.326) & 0.561 \\
\hline Others & 117(79.6) & $30(20.4)$ & 1 & & 1 & \\
\hline \multicolumn{7}{|l|}{ Education } \\
\hline Primary or below & 225(80.9) & $53(19.1)$ & $0.151(0.075-0.302)$ & $<0.001$ & $0.200(0.083-0.480)$ & $<0.001$ \\
\hline Junior & $70(84.3)$ & 13(15.7) & $0.119(0.050-0.282)$ & $<0.001$ & $0.107(0.041-0.276)$ & $<0.001$ \\
\hline High or above & 16(39.0) & $25(61.0)$ & 1 & & 1 & \\
\hline \multicolumn{7}{|l|}{ Residence } \\
\hline Urban & $93(70.5)$ & $39(29.5)$ & $1.758(1.087-2.844)$ & 0.021 & $1.169(0.653-2.096)$ & 0.599 \\
\hline Rural & 218(80.7) & $52(19.3)$ & 1 & & 1 & \\
\hline \multicolumn{7}{|l|}{ Living arrangements } \\
\hline Alone & $61(70.1)$ & 26(29.9) & $1.639(0.961-2.796)$ & 0.070 & $2.218(1.118-4.402)$ & 0.023 \\
\hline With children or others & $250(79.4)$ & $65(20.6)$ & 1 & & 1 & \\
\hline Insurance ${ }^{a}$ & & & & & NA & \\
\hline MIUR & $65(67.7)$ & $31(32.3)$ & $1.648(0.743-3.651)$ & 0.219 & & \\
\hline NCMS & $178(80.5)$ & 43(19.5) & $0.835(0.395-1.765)$ & 0.636 & & \\
\hline None & 18(81.8) & $4(18.2)$ & $0.768(0.215-2.746)$ & 0.684 & & \\
\hline Others & $12(85.7)$ & $2(14.3)$ & $0.576(0.112-2.970)$ & 0.510 & & \\
\hline MIUE & 38(77.6) & $11(22.4)$ & 1 & & & \\
\hline \multicolumn{7}{|l|}{ Household income $^{b}$} \\
\hline $\mathrm{Q}_{4}$ & $11(64.7)$ & $6(35.3)$ & $2.312(0.809-6.606)$ & 0.118 & $1.062(0.271-4.154)$ & 0.932 \\
\hline $\mathrm{Q}_{3}$ & $35(59.3)$ & $24(40.7)$ & $2.906(1.565-5.396)$ & 0.001 & $2.512(1.126-5.607)$ & 0.025 \\
\hline $\mathrm{Q}_{2}$ & $87(82.1)$ & 19(17.9) & $0.926(0.508-1.686)$ & 0.800 & $0.697(0.355-1.367)$ & 0.294 \\
\hline $\mathrm{Q}_{1}$ & 178(80.9) & $42(19.1)$ & 1 & & 1 & \\
\hline$N C D^{c}$ & & & & & NA & \\
\hline No & 21(91.3) & $2(8.7)$ & $0.310(0.071-1.349)$ & 0.119 & & \\
\hline Yes & $290(76.5)$ & $89(23.5)$ & 1 & & & \\
\hline
\end{tabular}

$O R_{C}$ crude odds ratio

$O R_{a}$ adjusted odds ratio

a NCMS New cooperative medical scheme, MIUR Medical insurance for urban residents scheme, MIUE Medical insurance for urban employee scheme

${ }^{\mathrm{b}} \mathrm{Quartile} 4(\mathrm{Q} 4)$ is the richest and Quartile 1 (Q1) is the poorest

${ }^{\circ} N C D$ Non-communicable chronic disease

institutional care is a good option for them because of the poor physical status, diminishing family size and reducing care functions [17, 32]. Another explanation may be the improvement of institutional service for seniors.
Particularly, integrated care in some nursing home which combined medical care with nursing services is preferred by disabled seniors with high household income. Furthermore, the support of government is a 
Table 4 Factors associated with willingness of institutional care among non-disabled seniors in Jiangsu, China, 2016 ( $n=2091$ )

\begin{tabular}{|c|c|c|c|c|c|c|}
\hline \multirow[t]{2}{*}{ Characteristics } & \multicolumn{2}{|c|}{ Willingness of institutional care } & \multirow[t]{2}{*}{$\mathrm{OR}_{C}(95 \% \mathrm{Cl})$} & \multirow[t]{2}{*}{$P$} & \multirow[t]{2}{*}{$\mathrm{OR}_{\mathrm{a}}(95 \% \mathrm{Cl})$} & \multirow[t]{2}{*}{$P$} \\
\hline & No (\%) & Yes (\%) & & & & \\
\hline$N=2091$ & 1827(87.4) & 264(12.6) & & & & \\
\hline Age & & & & & NA & \\
\hline $60-69$ & $666(86.2)$ & 107(13.8) & $1.188(0.762-1.852)$ & 0.448 & & \\
\hline $70-79$ & $954(88.1)$ & 129(11.9) & $1.000(0.647-1.545)$ & 0.999 & & \\
\hline $80+$ & 207(88.1) & 28(11.9) & 1 & & & \\
\hline Gender & & & & & NA & \\
\hline Male & $863(88)$ & $118(12)$ & $0.903(0.697-1.170)$ & 0.440 & & \\
\hline Female & $964(86.8)$ & $146(13.2)$ & 1 & & & \\
\hline \multicolumn{7}{|l|}{ Marital status } \\
\hline Married & 1432(88.4) & 187(11.6) & $0.670(0.502-0.893)$ & 0.006 & $0.770(0.553-1.072)$ & 0.121 \\
\hline Others & 395(83.7) & $77(16.3)$ & 1 & & 1 & \\
\hline Education & & & & & NA & \\
\hline Primary or below & 1159(87.3) & $169(12.7)$ & $1.234(0.808-1.885)$ & 0.330 & & \\
\hline Junior & $431(86.5)$ & $67(13.5)$ & $1.316(0.823-2.102)$ & 0.251 & & \\
\hline High or above & 237(89.7) & 28(10.6) & 1 & & & \\
\hline Residence & & & & & NA & \\
\hline Urban & 689(88.7) & 88(11.3) & $0.826(0.629-1.085)$ & 0.169 & & \\
\hline Rural & 1138(86.6) & 176(13.4) & 1 & & & \\
\hline \multicolumn{7}{|l|}{ Living arrangements } \\
\hline Alone & 199(81.9) & $44(18.1)$ & $1.636(1.147-2.335)$ & 0.007 & $1.392(0.927-2.088)$ & 0.111 \\
\hline With children or others & 1628(88.1) & 220(11.9) & 1 & & 1 & \\
\hline \multicolumn{7}{|l|}{ Insurance ${ }^{a}$} \\
\hline MIUR & 443(88.8) & $56(11.2)$ & $1.236(0.762-2.005)$ & 0.391 & $1.145(0.698-1.877)$ & 0.592 \\
\hline NCMS & 1010(86.5) & $158(13.5)$ & $1.530(0.995-2.351)$ & 0.053 & $1.274(0.792-2.048)$ & 0.317 \\
\hline Others & $50(84.7)$ & $9(15.3)$ & $1.760(0.781-3.967)$ & 0.173 & $1.643(0.719-3.752)$ & 0.239 \\
\hline None & $60(81.8)$ & 14(18.9) & $2.281(1.129-4.612)$ & 0.022 & $1.896(0.906-3.965)$ & 0.089 \\
\hline MIUE & 264(90.7) & $27(9.3)$ & 1 & & & \\
\hline \multicolumn{7}{|l|}{ Household income ${ }^{b}$} \\
\hline $\mathrm{Q}_{4}$ & $88(88)$ & $12(12)$ & $0.761(0.406-1.426)$ & 0.394 & $0.887(0.459-1.715)$ & 0.722 \\
\hline $\mathrm{Q}_{3}$ & 237(88.4) & $31(11.6)$ & $0.730(0.483-1.104)$ & 0.136 & $0.851(0.542-1.336)$ & 0.483 \\
\hline $\mathrm{Q}_{2}$ & 676(90.3) & $73(9.7)$ & $0.603(0.447-0.812)$ & 0.001 & $0.657(0.477-0.905)$ & 0.010 \\
\hline $\mathrm{Q}_{1}$ & $826(84.8)$ & 148(15.2) & 1 & & 1 & \\
\hline \multicolumn{7}{|l|}{$N C D^{c}$} \\
\hline No & 274(93.2) & 10(6.8) & $0.465(0.289-0.746)$ & 0.002 & $0.450(0.279-0.725)$ & 0.001 \\
\hline Yes & 1553(86.4) & 244(13.6) & 1 & & 1 & \\
\hline
\end{tabular}

$O R_{C}$ crude odds ratio

$O R_{a}$ adjusted odds ratio

a NCMS New cooperative medical scheme, MIUR Medical insurance for urban residents scheme, MIUE Medical insurance for urban employee scheme

${ }^{\mathrm{b}} \mathrm{Quartile} 4(\mathrm{Q} 4)$ is the richest and Quartile 1 (Q1) is the poorest

${ }^{\mathrm{N} C D}$ Non-communicable chronic disease

favorable objective factor. This finding suggests that it is urgent to make and modify different supporting policy for disabled and non-disabled seniors separately.

Similarly, the finding in this study was that household income level significantly determined the utilization willingness of institutional care both in disabled older adults whose household income was corresponding to Q3 and non-disabled seniors whose household income belonged to Q2. There are two possible explanations for such output. First, older adults with high household 
income would pay more attention to health status and quality of life, so the institution with better medical care and nursing service $[35,36]$ is favored by older adults, especially the disabled ones with poor mental and physical condition. However, disabled seniors with higher household income which are enough to afford private professional care may have other options other than institutional care [37]. Second, many poor seniors have to give up their idea of institutional care because of financial insolvency, but if older people are the poorest ones, the willingness of institutional care may increase because the country is guaranteeing the rights of them through policy orientation. The finding indicates that maybe the government should pay special attention to the willingness of institutional care among middle-income seniors, which is an important question worthy of further exploration.

Furthermore, the study demonstrated that the preference for institutional care of disabled seniors was also found to be significantly related to three indicators including age, living arrangement, and education, which was consistent with previous studies [17, 18]. Education exerts a statistically positive effect on the willingness. The seniors with better education are open-minded, who will be easily to accept the new idea in view of diminishing family size and increasing geographic mobility [35]. In addition, disabled seniors living alone were more likely to choose institutional care because they find it hard to obtain informal support [30, 38].

Interestingly, age had a negative impact on the willingness for institutional care among disabled seniors. Essentially, with the growth of age, physical and psychological health of old adults become poor, leading to high demand and willingness of institutional care. However, the result of the study is opposite, which may be explained by Chinese traditional culture and changes of family structure [39]. Most of the oldest old tend to reject institutional care because of traditional family norms, intense loneliness, and extreme insecurity causes. Meanwhile, the young older people are more likely to accept the concept of modern pension institution [40]. The findings should, therefore, give an impetus to attach importance to the traditional culture and family concept in the study of willingness to live in eldercare institution.

Parallel to other studies $[15,18]$, we found that the non-disabled seniors who suffered from NCDs were more likely to prefer institutional care. The possible reason is that some NCDs are strongly related to worse physical condition which needs professional institutional service, including dementia, cardiovascular diseases and arthritis [41, 42]. According to the WHO Global Status Report (2010), NCDs are the leading causes of mortality and disability globally [43]. China, as the most populous developing country, has experienced the heavy burden of
NCDs, accounting for $70 \%$ of total disease burden and $80 \%$ of total death [44]. However, for disabled seniors, 94.3\% among them had NCDs according to the sample, leading to the possibility of neglecting the effect of NCDs. The finding shows that it is urgent to do further research to have a better understanding of epidemiology of NCDs among older adults.

This study has some limitations. Firstly, the information including the economic status and willingness of institutional care were self-reported, leading to the possibility of bias. Secondly, a cross-sectional design was adopted in our study to illustrate the relationship between willingness of institutional care and ADL disability difference rather than causality. Thirdly, some important variables are unavailable in the current study, such as the understanding of the institutional care [45], information of the offspring [17] and the psychological status $[13,16]$, which are the research directions in the future..

\section{Conclusion}

This study showed that the willingness for institutional care among disabled seniors was significantly higher than that among non-disabled ones. Household income was found to be an important determinant for the willingness in both disabled and non-disable seniors. Additionally, age, living arrangement, and education were predictors for willingness among disabled seniors. Non-disabled seniors who had NCDs were more likely to choose institutional care. According to the findings, several countermeasures should be put forward. Targeting policies should be made or modified to satisfy various demands of the disabled and non-disabled seniors separately.

\section{Abbreviations}

ADL: Activity of Daily Living; MIUE: Medical Insurance for Urban Employee Scheme; MIUR: Medical Insurance for Urban Residents Scheme; NCDs: NonCommunicable Disease; NCMS: New Cooperative Medical Scheme;

ORa: Adjusted Odds Ratio; ORc: Crude Odds Ratio

\section{Acknowledgments \\ None}

\section{Authors' contributions}

CQW took responsibility for the integrity of the research. CQW, NC and CCZ conceived the idea. CQW, NC, XL and NY implemented the investigation. $N C, X L, N Y$ and $C C Z$ took part in the statistical analysis and interpreted the results. NC drafted the manuscript. CQW and XL gave lots of comments and polished the draft. All authors read and approved the final manuscript.

\section{Funding}

The project was supported by the grant of National Social Science Foundation of China (Nos:15CRK015) and National Nature Science Foundation of China (Nos:71573139). The granting agencies did not have roles in the design, collection, analysis, and interpretation of data or in writing the manuscript. 


\section{Ethics approval and consent to participate}

The Ethical Committee of Nanjing University of Chinese Medicine approved the study protocol. Participants were informed about the aim of the survey, the selection criterion of the sample, and the assurance that the information was only used for research. Furthermore, the proxy consent procedure was given for those participants who were considered cognitively impaired. All participants gave written informed consent before inclusion in the study.

\section{Consent for publication}

Not applicable.

\section{Competing interests}

The authors declare that they have no competing interests.

\section{Author details}

${ }^{1}$ School of Health Economics and Management, Nanjing University of Chinese Medicine, Nanjing 210023, People's Republic of China. ${ }^{2}$ School of Pharmacy, Nanjing Medical University, Nanjing 211166, People's Republic of China. ${ }^{3}$ School of Public Health, Dalian Medical University, Dalian 116044, People's Republic of China. ${ }^{4}$ School of Public Health, Shandong University, 44 Wen-hua-xi Road, Jinan 250100, Shandong, China. ${ }^{5}$ Nanjing Medical University, 101 Longmian Road, Nanjing 211166, Jiangsu, China.

Received: 22 March 2019 Accepted: 13 June 2019

\section{Published online: 24 June 2019}

\section{References}

1. Kinsella KG, Velkoff VA. An aging world. Washington, DC: U.S. Department of Commence, Economics and Statistics Administration, U.S. Census Bureau; 2001.

2. China, National Bureau of Statistics. National data (2016). Retrieved from http://data.stats.gov.cn/easyquery.htm?cn=C01

3. New York: United Nations: United Nations Department of Economic and Social Affairs. World population prospects: the 2010 revision.2011.

4. Yang $M$, Ding $X$, Dong B. The measurement of disability in the elderly: a systematic review of self-reported questionnaires. J Am Med Dir Assoc. 2014;15:150.e151-9.

5. China, National Commission on Ageing. Three Departments Issued the Fourth Sample Survey on the Living Conditions of the Elderly in Urban and Rural China. Available at http://www.cncaprc.gov.cn/contents/2/177118.html

6. Liu T, Sun L. An apocalyptic vision of ageing in China: old age care for the largest elderly population in the world. Z Gerontol Geriatr. 2015;48:354-64.

7. $\mathrm{Ku} \sqcup$, Liu LF, Wen MJ. Trends and determinants of informal and formal caregiving in the community for disabled elderly people in Taiwan. Arch Gerontol Geriatr. 2013;56:370-6.

8. Zhang H. Who will care for our parents? Changing boundaries of family and public roles in providing care for the aged in urban China. Care Manag J. 2007:8:39-46.

9. Zhang NJ, Guo M, Zheng X. China: awakening giant developing solutions to population aging. Gerontologist. 2012;52:589-96.

10. Zhuang X, Zhang L. Aged-support situations of the disabled elderly. Popul J. 2016:38:47-57.

11. Zhou X, Zhang Y. Rural elderly people of institutional care wishes and impacting factor: based on the 346 questionnaire data of ChangshaZhuzhou-Xiangtan areas. J Hunan Agric Univ. 2015;16:62-5.

12. Yao Z, Wang $S$. Willingness and influencial factors of the rural aged to be supported by institutional care: based on the survey of 749 rural aged in the east region. J Hunan Agric Univ. 2012;13:39-44.

13. Qian Y, Chu J, Ge D, Zhang L, Sun L, Zhou C. Gender difference in utilization willingness of institutional care among the single seniors: evidence from rural Shandong, China. Int J Equity Health. 2017;16:77.

14. He Y, Jing Z, Yuan X. A study on the factors associated with preferences for institutional care of the elderly in urban China:evidences from Guizhou. Chin J Gerontol. 2013;33:5405-6.

15. Gao R, Guo J, Shen Y, Hu S, Dong Y, Zhuang L, Wang H, Luo S. Willingness and influencial factors of the urban aged to be supported by institutional care: based on the survey of Shandong province. J Community Med. 2014; 12:17-9.

16. Zhang R. Analysis on preferences for institutional care model of the elderly: evidences from 12 cities in Henan province. World Surv Res. 2015;12:13-7.
17. Xiao Y, Sui S. Analysis on preferences for institutional care model of disabled elderly in China from the perspective of the new welfare economics. Popul Develop. 2017;23:91-9.

18. Zhang W, Wei M. A study on the factors associated with preferences for institutional care of the elderly in urban China:evidences from Xicheng district of Beijing. Popul Econ. 2014;6:22-34.

19. Nanjing: Jiangsu: Jiangsu civil affair bureau. The report on the elderly of Jiangsu in 2015.2016.

20. Sunil TS, Rajaram S, Zottarelli LK. Do individual and program factors matter in the utilization of maternal care services in rural India?: a theoretical approach. Soc Sci Med. 2006;62:1943-57.

21. Zhou C, Ji C, Chu J, Medina A, Li C, Jiang S, Zheng W, Liu J, Rozelle S. Nonuse of health care service among empty-nest elderly in Shandong, China: a cross-sectional study. BMC Health Serv Res. 2015;15:294.

22. Katz $\mathrm{S}$, Ford $A B$, Moskowitz RW, Jackson BA, Jaffe MW. Studies of illness in the aged. The index of ADL: a standardized measure of biological and psychosocial function. JAMA. 1963;185:914-9.

23. Chou KL, Leung JC. Disability trends in Hong Kong community-dwelling Chinese older adults: 1996, 2000, and 2004. J Aging Health. 2008;20:385-404.

24. Alexandre Tda S, Corona LP, Nunes DP, Santos JL, Duarte YA, Lebrao ML. Gender differences in incidence and determinants of disability in activities of daily living among elderly individuals: SABE study. Arch Gerontol Geriatr. 2012;55:431-7.

25. Ge D, Chu J, Zhou C, Qian Y, Zhang L, Sun L. Rural-urban difference in the use of annual physical examination among seniors in Shandong, China: a cross-sectional study. Int J Equity Health. 2017;16:86.

26. Chen W, Fang Y, Mao F, Hao S, Chen J, Yuan M, Han Y, Hong YA. Assessment of disability among the elderly in Xiamen of China: a representative sample survey of 14,292 older adults. PLoS One. 2015;10: e0131014.

27. Jang Y, Kim G, Chiriboga DA, Cho S. Willingness to use a nursing home: a study of Korean American elders. J Appl Gerontol. 2008;27:110-7.

28. Chung MH, Hsu N, Wang YC, Lin HC, Huang YL, Amidon RL, Kao S. Factors affecting the long-term care preferences of the elderly in Taiwan. Geriatr Nurs. 2008;29:293-301.

29. She J, M WR, Cheng Y. Aging at home and the intent to relocate in Beijing. Prog Geogr. 2015;34:1577-85.

30. Qian Y, Qin W, Zhou C, Ge D, Zhang L, Sun L. Utilisation willingness for institutional care by the elderly: a comparative study of empty nesters and non-empty nesters in Shandong, China. BMJ Open. 2018;8:e022324.

31. Jiang $Y$, Si W. Analysis of the factors influencing on elder' s preferences for social care- empirical evidence from Zhejiang province. Popul Econ. 2006;3: $8-12$.

32. Song B. Research on the choice of pension services of disabled elders in rural areas. Lanzhouxuekan. 2016;2:137-43.

33. Williams A, Straker JK, Applebaum R. The nursing home five star rating: how does it compare to resident and family views of care? Gerontologist. 2016; 56:234-42.

34. Zhan HJ, Liu G, Guan X, Bai HG. Recent developments in institutional elder care in China: changing concepts and attitudes. J Aging Soc Policy. 2006;18: $85-108$.

35. Huang J, Li F. The impact of life satisfaction on the willingness of the old to live in the elderly nursing home: an investigation of the rural elderly in Jiangsu. South China Popul. 2013;28:28-38.

36. Xiao Y, Lv Q, Qi M. Factors affecting the oldest olds willingness to entering institutions for elderly: a case study on the main city area of Chongqing northwest popul; 2012. p. 27-30+35.

37. Li M, Zhang Y, Zhang Z, Zhang Y, Zhou L, Chen K. Rural-urban differences in the long-term care of the disabled elderly in China. PLoS One. 2013;8: e79955.

38. Cai Q, Salmon JW, Rodgers ME. Factors associated with long-stay nursing home admissions among the U.S. elderly population: comparison of logistic regression and the cox proportional hazards model with policy implications for social work. Soc Work Health Care. 2009;48:154-68.

39. Yeboah C, Bowers B, Rolls C. Culturally and linguistically diverse older adults relocating to residential aged care. Contemp Nurse. 2013;44:50-61.

40. Gu D, Dupre ME, Liu G. Characteristics of the institutionalized and community-residing oldest-old in China. Soc Sci Med. 2007;64:871-83.

41. Lafortune $\mathrm{G}$, Balestat $\mathrm{G}$. Trends in severe disability among elderly people: assessing the evidence in 12 OECD countries and the future implications; 2007 
42. Wang H, Chen K, Pan Y, Jing F, Liu H. Associations and impact factors between living arrangements and functional disability among older Chinese adults. PLoS One. 2013;8:e53879.

43. World Health Organization. The top 10 causes of death. Available at http:// www.who.int/mediacentre/factsheets/fs310/en/

44. China's major health challenge: control of chronic diseases. Lancet. 2011; 378:457.

45. Tang $Y$, Yang $H$, Wang $X$, Shi $Y$. Research progress of the willingness to stay in institutions among seniors and its influencing factors. Nurs J Chin PLA. 2014:31:37-39+43.

\section{Publisher's Note}

Springer Nature remains neutral with regard to jurisdictional claims in published maps and institutional affiliations.

Ready to submit your research? Choose BMC and benefit from:

- fast, convenient online submission

- thorough peer review by experienced researchers in your field

- rapid publication on acceptance

- support for research data, including large and complex data types

- gold Open Access which fosters wider collaboration and increased citations

- maximum visibility for your research: over $100 \mathrm{M}$ website views per year

At $\mathrm{BMC}$, research is always in progress.

Learn more biomedcentral.com/submissions 